\title{
Placenta previa : An ultimate everlasting obstetric emergency
}

\author{
Original \\ Hossam H. Soliman \\ Article \\ Department of Obstetrics \& Gynecology, Al-Galaa Maternity Teaching Hospital, Egypt
}

\begin{abstract}
Objective: The current study is a cohort observational prospective study with the aim of assessment and auditing of the detrimental effects and consequences of placenta previa (PP), which is considered by most obstetricians an ultimate obstetric risky condition, top surgical emergency and stressful condition for both the patient as well as the obstetrician. Such condition despite being linked to previous surgeries resulting in uterine wall scarring, yet considerably many cases with no previous uterine surgeries are presenting with such condition.

Patients and Methods: Two groups of patients; group (A) including 89 patients diagnosed with PP at/or near full term and group (B) included 82 patients with high order (repeated) cesarean section (CS) were followed prior to, during and after delivery via CS with specific predetermined parameters such as hemoglobin level, postpartum hysterectomy, amount of blood transfusion and neonatal NICU admission. Those parameters used for assessment of the deleterious effects of both conditions on both the mother and newborn and both conditions were compared for the extremity of hazard.

Results:There was considerably significant drop in HB level and amount of blood transfusion between both groups with drop of $\mathrm{HB}$ level from $11.7 \mathrm{gm} / \mathrm{dl}$ to $9 \mathrm{gm} / \mathrm{dl}$ in group A ladies, whereas group B ladies had a drop from $11.8 \mathrm{gm} / \mathrm{dl}$ to $10.1 \mathrm{gm} / \mathrm{dl}$. Also, 35 mothers needed blood transfusion in group A compared to 6 mothers in group B. Furthermore, 7 ladies had their uterus removed in group A as a salvage procedure compared to 1 lady in group B. Concerning NICU admission, 28 neonates for the mothers in group A were admitted to the NICU compared to 12 in group B.

Conclusion: PP was recognized to be an obstetrical condition with ultimate risk to both the mother and newborn in comparison to other well-known high risk obstetrical conditions such as high order (multiple repeated) cesarean delivery.
\end{abstract}

Key Words: Blood transfusion, cesarean hysterectomy, maternal mortality, placenta previa

Received: $15^{\text {th }}$ March 2019, Accepted: $19^{\text {th }}$ April 2019

Corresponding Author: Hossam H. Soliman, Department of Obstetrics \& Gynecology, Al-Galaa Maternity Teaching Hospital, 26 July St., Cairo, Egypt, Tel.: +2012/22432352, E-mail: hossamsoly@yahoo.com

ISSN: 2090-7625, November 2019, Vol.9, No. 4

\section{INTRODUCTION}

Placenta previa (PP) is defined as an obstetric condition with the placenta implanted at the lower segment of the uterus close to/or covering the cervix at/or few weeks near to full term, usually obstructing the normal path of delivery via the cervical canal ${ }^{[1,2]}$. Such condition is frequently associated with placental villi penetrating through the decidua basalis towards variable degree of endometrial and myometrial invasion leading to what is known as placenta accrete and increta ${ }^{[3]}$.Placenta previa is well recognized as a leading cause of severe antepartum hemorrhage and associated with major maternofetal morbidity and mortality ${ }^{[4]}$.

Variable incidence of placenta previa was reported during the past decades with figures ranging between as low as 4 per 1000 pregnancies $^{[1]}$, to as high as $1.65 \% \%^{[5,6]}$.
Many causes were identified as risk factors that contribute to the increased incidence of placenta previa through increasing endometrial and uterine fibrous and scar tissue. The condition was found to be associated more with pregnant ladies having a previous history of placenta previa, cervical dilatation and curettage of uterine cavity for any reason. Ladies with high order cesarean section (CS) delivery, myomectomy, metroplasty, elderly age and multiparity were recognized as possible predisposing factors for placenta previa ${ }^{[7,8]}$.

Other risk factors including multiple gestation, malpresentation and diabetes mellitus ${ }^{[9,10]}$ were observed. Variable complications were reported to occur with placenta previa and lead to diverse maternal and fetal hazardous outcome including hemorrhagic shock, postpartum hemorrhage, anemia, caesarean hysterectomy, low birth weight and maternal and perineal death ${ }^{[11]}$. 
There is an increasing maternal and fetal risks with repeated high order CS when compared to previous one cesarean or vaginal delivery ${ }^{[12]}$.There is an increasing technical difficulty with higher order CS that could be attributed to extensive adhesions leading to difficulty in dissecting the adherent pelvic organs away from the uterus with increase in the operative duration and amount of blood $\operatorname{loss}^{[13]}$.

\section{PATIENTS AND METHODS}

A cohort observational prospective study was done between January 2013 and June 2016 in a tertiary hospital in Jeddah, kingdom of Saudi Arabia aiming to assess the incidence and adverse outcome of placenta previa through a follow up of all the cases presented with placenta previa and delivered at the hospital. The study was commenced following getting the necessary approval from the ethical committee of the hospital. The cases who were diagnosed with persistence of the condition on ultrasound exam at 34 weeks of gestation were followed up till delivery. The placenta was measured for the distance between its edge and the internal cervical oss (IOS), the main term of inclusion was a placenta implanted less than $5 \mathrm{~cm}$ from the internal oss and including placentas covering partially or completely the IOS and preceding below the presenting part. All the demographic data, history of previous operations, relevant medical or surgical intervention that might be considered as a predisposing factor. The collected data after delivery and settling of the patient condition following delivery were gathered and analyzed. Those data included hematological studies and the neonatal outcome, in addition to any further surgical intervention that was not considered at the very beginning and was adopted during the main operation or thereafter and was part of a salvage procedure to save the patient's life. The collected data included:

- Maternal age

- Gestational age at delivery

- Parity

- Relation of the placenta to the closed internal oss.

- Previous CS order

- Previous myomectomy

- Previous Dilatation and Curettage

- Previous history of retained placenta

- Uterine anomalies

- Abnormal neonatal presentation

- Multiple gestation

- Hemoglobin percentage before and after operation $(\mathrm{HB} \%)$

- History of blood disease that might lead to bleeding tendency

- Duration of surgery

- Units of blood transfused during or after the operation

- Postpartum hysterectomy

- Intra uterine fetal death

- Maternal ICU admission and fetal NICU admission

- Maternal mortality
Those cases were compared to controls of patients with high order cesarean delivery, with previous 4 or more cesareans.

\section{Statistical analysis}

IBM SPSS statistics (V.25.0, IBM corp, USA, 2017-2018) was used for data analysis. Data were expressed as mean $\pm \mathrm{SD}$ for quantitative parametric measures in addition to both number and percentage for categorized data. The following tests were done:

1.Comparison between two independent mean groups for parametric data using student t-test.

2.Chi-Square test to study the association between each 2 variables or comparison between 2 independent groups as regards the categorized data.

The probability of error at 0.05 was considered sig, while at 0.01 and 0.001 are highly significant.

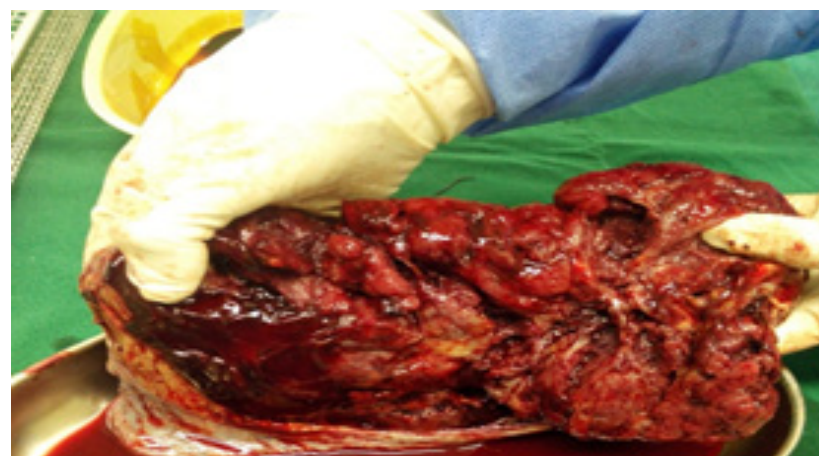

Fig 1: Picture of postoperartive placenta previa accrete with defective placenta

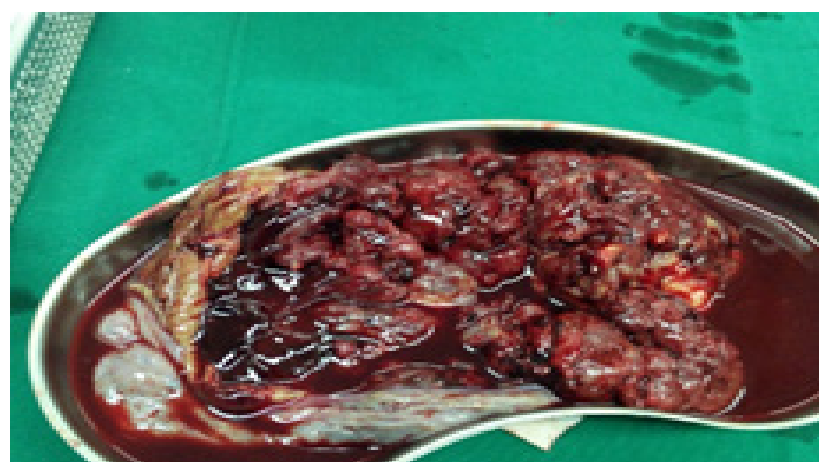

Fig 2: Other picture of a case of placeta previa accrete with missing lobes

\section{RESULTS}

In the current study, the main study groups were designated into; group A including all the cases presented with any degree of placenta previa, whereas group B was considered another proven high-risk group for comparison and control and was composed of pregnant ladies with high order cesarean section at/or near to full term.

Group A patients had an age range between 21 and 42 with 45 patients above 29 years of 
age. Most of the patients of group A (48 patients) had previous 3 or 4 deliveries; while 62 cases had either no or previous $1 \mathrm{CS}$. The amount of transfused blood ranged between 500 and $3000 \mathrm{ml}$, with a mean of 1157.66 of transfused blood. Operative duration ranged between 53 minutes and a maximum of 236 minutes, with a mean duration of 90.93 minutes. Fetal weight at delivery had a minimum of 1930 and a maximum of 3230, with a mean value of 2531.193 grams. Also, there was no significant difference in the incidence of bladder or intestinal injury, with 3 cases of bladder injury in group A compared to 2 cases in group B, with a percentage of $2.64 \%$ and $1.64 \%$, respectively. Also, there were 2 cases of small intestine injury in each group and 1 case of colon injury in group B. Figures 1 and 2 both show placenta previa accrete post-delivery, whereas Tables 1 and 2 show the variable demographic, clinical, operative, pre and postoperative criteria of both groups. Figures 3, 4,5 and 6 simply demonstrate the difference between both groups concerning operative blood loss, intra and postoperative blood transfusion, operative duration, and fetal growth.

Table 1: Variable demographic criteria, hematologic condition, operative duration using student T-test

\begin{tabular}{|c|c|c|c|c|c|c|c|}
\hline & Group & Number & Mean & St.D & T-test value & $P$ value & Significance \\
\hline \multirow{3}{*}{ Age } & Group A & 88 & 29.74 & 4.471 & \multirow{3}{*}{-10.792} & \multirow{3}{*}{0} & \multirow{3}{*}{ HS } \\
\hline & & & & & & & \\
\hline & Group B & 82 & 37.16 & 4.487 & & & \\
\hline \multirow{3}{*}{$\begin{array}{l}\mathrm{HB} \text { grams } \% \\
\text { before delivery }\end{array}$} & Group A & 88 & 11.756 & 0.6253 & \multirow{3}{*}{-0.547} & \multirow{3}{*}{0.585} & \multirow{3}{*}{ NS } \\
\hline & & & & & & & \\
\hline & Group B & 82 & 11.816 & 0.7919 & & & \\
\hline \multirow{3}{*}{$\begin{array}{l}\text { HB grams \% } \\
\text { after delivery }\end{array}$} & Group A & 88 & 9.027 & 0.9548 & \multirow{3}{*}{-7.451} & \multirow{3}{*}{0} & \multirow{3}{*}{ HS } \\
\hline & & & & & & & \\
\hline & Group B & 82 & 10.124 & 0.9635 & & & \\
\hline \multirow{3}{*}{$\begin{array}{l}\text { Blood } \\
\text { transfusion in } \\
\text { millimeters }\end{array}$} & Group A & 35 & 1157.14 & 625.405 & \multirow{3}{*}{2.538} & \multirow{3}{*}{0.015} & \multirow{3}{*}{ S } \\
\hline & & & & & & & \\
\hline & Group B & 6 & 600 & 219.089 & & & \\
\hline \multirow{3}{*}{$\begin{array}{l}\text { Operative } \\
\text { duration in } \\
\text { minutes }\end{array}$} & Group A & 88 & 90.93 & 41.6 & \multirow{3}{*}{3.638} & \multirow{3}{*}{0} & \multirow{3}{*}{ HS } \\
\hline & & & & & & & \\
\hline & Group B & 82 & 73.02 & 19.351 & & & \\
\hline \multirow{3}{*}{$\begin{array}{l}\text { Fetal weight } \\
\text { at delivery }\end{array}$} & Group A & 84 & 2651.73 & 309.333 & \multirow{3}{*}{-8.052} & \multirow{3}{*}{0} & \multirow{3}{*}{ HS } \\
\hline & & & & & & & \\
\hline & Group B & 82 & 3111.52 & & & & \\
\hline
\end{tabular}

Table 2 : Comparison of associated complication for mother and neonate of both groups using Pearson Chi-square test

\begin{tabular}{lccccc}
\hline & Groups & Number & Value & P value & Significance \\
\hline Parity $\leq 4$ & Group A & 47 & & & \\
& Group B & 0 & 60.530 & 0.000 & HS \\
Parity $>4$ & Group A & 41 & & & \\
& Group B & 82 & & &
\end{tabular}




\begin{tabular}{|c|c|c|c|c|c|}
\hline $\mathrm{CS}$ order $\leq 4$ & Group A & 82 & & & \\
\hline & Group B & 147.608 & 147.608 & 0.000 & HS \\
\hline $\mathrm{CS}$ order $>4$ & Group A & 6 & & & \\
\hline & Group B & & & & \\
\hline Myomectomy & Group A & 5 & 0.013 & 0.908 & NS \\
\hline & Group B & 5 & & & \\
\hline Multiple gestation & Group A & 7 & 0.223 & 0.637 & NS \\
\hline & Group B & 5 & & & \\
\hline ICU admission & Group A & 22 & 9.647 & 0.002 & $\mathrm{~S}$ \\
\hline & Group B & 6 & & & \\
\hline Post-partum & Group A & 7 & 4.294 & 0.038 & $\mathrm{~S}$ \\
\hline & Group B & 1 & & & \\
\hline Intrauterine & Group A & 4 & 0.085 & 0.771 & NS \\
\hline & Group B & 3 & & & \\
\hline Fetal NICU & Group A & 28 & 6.966 & 0.008 & $\mathrm{~S}$ \\
\hline & Group B & 12 & & & \\
\hline Preterm labor & Group A & 24 & 7.207 & 0.007 & $\mathrm{~S}$ \\
\hline & Group B & 9 & & & \\
\hline Blood transfusion & Group A & 35 & 24.432 & 0.0001 & HS \\
\hline & Group B & & & & \\
\hline
\end{tabular}

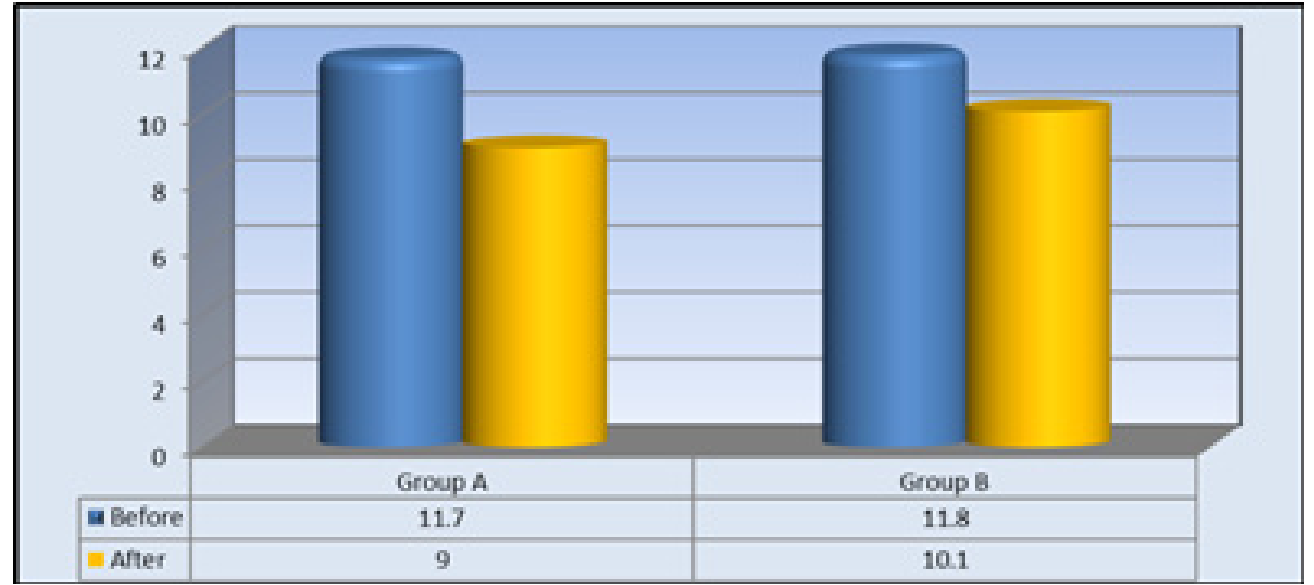

Fig. 1 : Diagram of HB\% before and after caesarean delivery in both group A and group B 


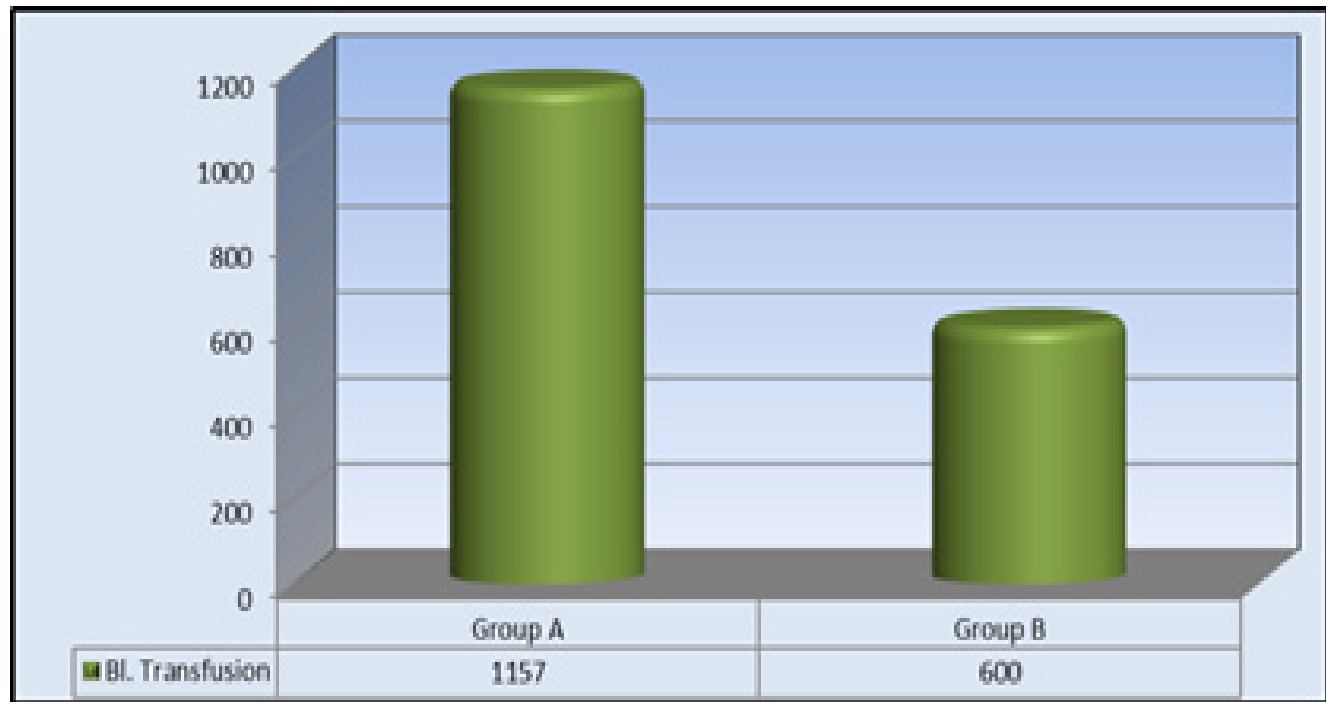

Fig. 2 : The mean of the amount of transfused blood in both group A and group B

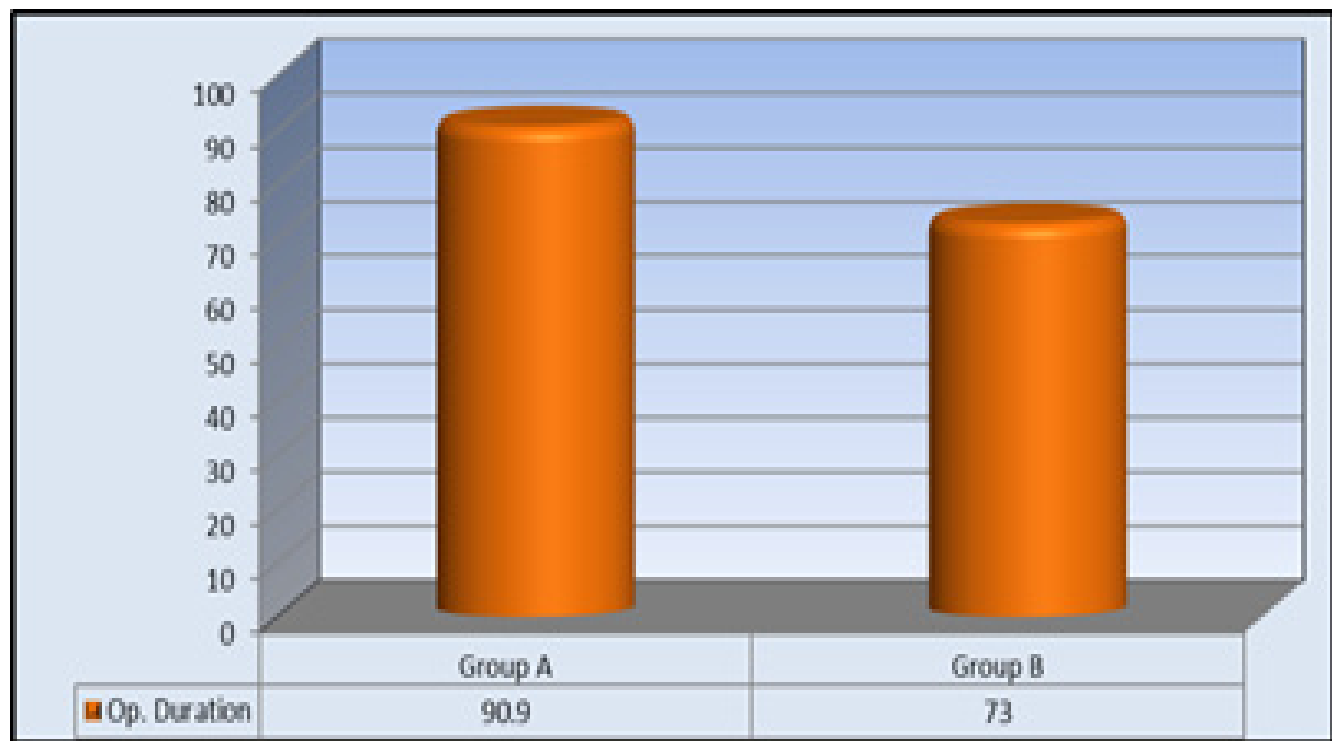

Fig. 3: Diagram of $\mathrm{HB} \%$ before and after caesarean delivery in both group A and group B

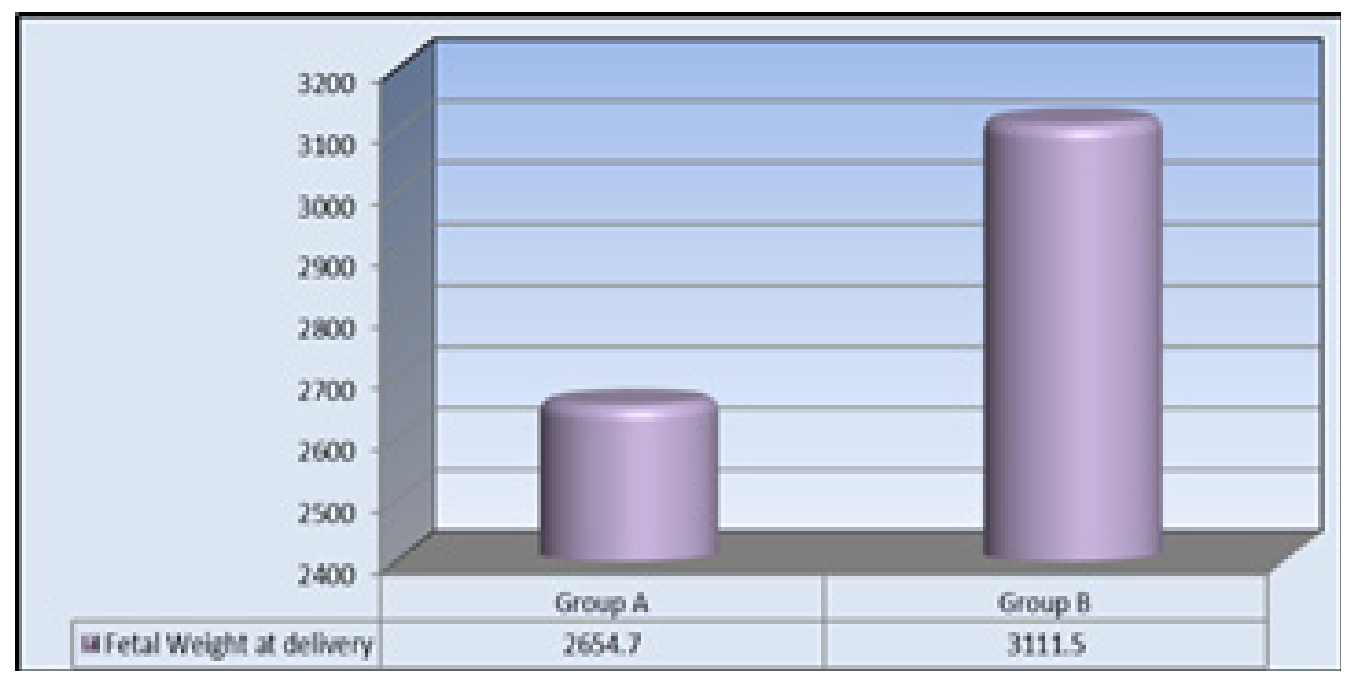

Fig. 4: The mean of the amount of transfused blood in both group A and group B 


\section{DISCUSSION}

The incidence of placenta previa is increasing all over the world, that is attributed in part to the increasing rate of cesarean delivery ${ }^{[14]}$. Placenta previa has an adverse effects and serious deleterious implications on both the mother and neonate, with more susceptibility to intra uterine gross restriction (IUGR), preterm labor, intra uterine fetal death, intrapartum and postpartum hemorrhage as well as with consequential massive blood transfusion, postpartum hysterectomy and even maternal mortality ${ }^{[15,16]}$.

Repeated CS is also considered one of the major causes contributing to maternal and neonatal morbidity and mortality ${ }^{[17]}$.Such repeated CS delivery is considered to be associated with diverse complications including extensive abdominal adhesions entangling the bladder and bowel and predisposing to bladder, ureteric and intestinal injuries. In addition to the high probability of uterine dehiscence and rupture, with consequential morbid hemorrhage and cesarean hysterectomy looming as a result, postoperative complications such as wound infection, thromboembolism, either are not far from happening ${ }^{[18]}$.

In a study by Arein FR et al. ${ }^{[19]}$ addressing the condition of PP delivered by C.S, it was found that $78.4 \%$ of that cases developed this condition after a previous CS, non-matching with the current study in which $48(54.5 \%)$ ladies out of 88 with PP were identified without a previous history of C.S delivery, while $45.5 \%$ had a previous history of C.S delivery. One hundred and fifty cases with primary postpartum hemorrhage were recorded. In the current study, there were only $35(39.7 \%)$ patients out of 88 cases with massive bleeding requiring blood transfusion of 1-6 units of blood. That is much less than the cases of Arein FR study with $122(57.46 \%)$ patients who received 3-8 units of transfused blood. A very high incidence of post-partum hysterectomy was reported by them with 56 patients $(26.2 \%)$, undergone hysterectomy as a salvage procedure in a clear non-concordance with the current discussed and presented study in which only $7(8 \%)$ of the cases had their uterus removed as a salvage measure for uncontrollable intractable postpartum hemorrhage. There were no considerable differences between both studies concerning urinary tract injuries and maternal mortality.

In another study by Anzaku AS and Musa J. ${ }^{[8]}$, one hundred and thirty-five ladies out of 10,895 maternal birth deliveries were identified to have PP with a mean age of 30.2. The majority of them $92(68.2 \%)$ were of a parity 1-4 matching with the current study in which the mean patient's age was 29.74 and $63(71.7 \%)$ ladies had a parity of 1-4. Anzaku and his fellow identified $\mathrm{CS}$ as a risk factor with an incidence of previous C.S of $40.7 \%$, grand multiparity with a $28.3 \%$ incidence and multiparity to exist in $6.2 \%$ of cases with no identifiable risk factor in 50 patients $(37 \%)$. In the current presented study, 40 patients $(45.5 \%)$ identified with previous CS, while $41(46.5 \%)$ patients were grand multipara and $7(8 \%)$ are with multiple pregnancy while $34(38.6 \%)$ are without identifiable risk factors. Anzaku also mentioned that $11.9 \%$ have postpartum anemia, in contradiction to the present study in which a rate of switching to a state of postpartum anemia with hemoglobin (HB) less than $10 \mathrm{mg} / \mathrm{dl}$ was seen in $67(75 \%)$ of patients and only 7 patients $(8 \%)$ undergone postpartum hysterectomy.

In another study done by Kallmann M. et al. ${ }^{[20]}$ between 1993 and 2012, a number of 328 pregnant ladies were identified with placenta previa, with an incidence of $0.15 \%$ for the condition and an overall average maternal age of 31.6 , which is well comparable to the mean age of 29.8 in the present study. In the study by Kallmann, 23(7.1) had massive postpartum hemorrhage and 98 (30\%) were anemic and 17 cases $(5.2 \%)$ hysterectomy was done with no maternal death recorded in the population of study. A total of $179(54.9 \%)$ were born $<37$ weeks of gestation in the current study $24(27.3 \%)$ preterm neonates were delivered. Also, there was 7 cases $(8 \%)$ for whom hysterectomy was done, out of the total 89 study cases and the mean birth weight was 2651 gms, which is comparable to the mean neonatal birth weight of 2692 gms in the study by Kallmann.

In comparison to group B which is composed of pregnant ladies with high order CS, 35 patients out of 89 in group A had blood transfusion compared to only 6 patients in group $B$ out of 82 with a $P$ value $<0.001$.Operative duration for group A had a mean duration of 90.93 minutes, whereas for group B it was 73.02 minutes with a remarkably significant difference between both groups. Fetal weight as well was with high significant difference between both groups with neonatal birth weight mean value in group A of 2651.73 gms compared to $3111.52 \mathrm{gms}$ in group B. Concerning HB level in group A, the mean was 11.756 preoperative, dropping to 9.027 postoperative, whereas for group $\mathrm{B}$, the mean $\mathrm{HB}$ was 11.816 preoperative dropping to 10.124 postoperative. Twenty-two patients in group A were admitted to the ICU in comparison to 6 patients in group $\mathrm{B}$ with a highly significant difference significant difference value of 0.002 . Also, there is a significant difference in the number of cases who had their uterus removed with 7 cases in group A (8\%) compared to only 1 case in group B $(1.2 \%)$, with a $P$ value of 0.038 . 


\section{CONCLUSION}

PP represents a top obstetrical emergency carrying utmost risk for both the mother and newborn and can carry a detrimental consequence. A conclusion can be reached, that although such condition is totally un-frequent and with a low incidence, yet it imposes great stress for the obstetrician and enormous dread for the pregnant ladies having such condition.

\section{CONFLICT OF INTEREST}

There are no conflicts of interest.

\section{REFERENCES}

1. Faiz AS and Ananth CV. Etiology and risk factors for placenta previa: An overview and meta-analysis of observational studies. Journal of Maternal-Fetal and Neonatal medicine.2003;13:175-190.

2. Cresswell JA, Ronsmons C, Calvert C. et al. Prevalence of placenta previa by world region. A systematic review and meta-analysis. Tropical medicine and international health.2013;18:712-724.

3. Miller DA, Challet JA and Goodwin TM. Clinical risk factors for placenta previa-placenta accrete. AmJ Obstet Gynecol.1997;177: 210-14.

4. Buroda AT and Shehu CE. Placenta previa at Usman Danfodiyo university teaching hospital, Sokoto: A5 year review. Sahel medical Journal. 2013;16: 5659-.

5. Loto $\mathrm{O}$ and Onile TG. Placenta previa at the Obafeni Awolowo university teaching hospitals. Complex,.Aten year analysis. Niger J Clinic pract. 2008; 11: 130-3.

6. Ezechi OC, Kalu BK, Nwokora CA et al. Placenta previa : Astudy of risk factors, maternal and fetal outcome. Trop J Obstet Gynecol.2004; 21:2.

7. Tuzovic L, Dienis J and LIIGI CM. Obstetric risk factors associated with placenta previa development: Case-control study. Croat Med J.2003; 44 :728-733.

8. Anzaku AS and Musa J.Placenta previa: Incidence, risk factors, maternal and fetal outcomes in a Nigerian teaching hospital. Journal of medicine(AJOL). 2012;6:42-46.

9. Bener A, Saleh NM and Yousafzal MT. Prevalence and associated risk factors of anti-partum hemorrhage among Arab women in an economically growing fast society. Nigerian journal of clinical practice. 2012; 15: 185-9.

10. Dwivedi S, Verma $\mathrm{K}$, Johan $\mathrm{U}$, et al. Implications of placenta previa on pregnancy outcome: A prospective study. Indian Journal of Obstetrics and Gynecology research; January-March 2018;5(1): 93-97.

11. Sinha P and Kuruba N. Antepartum hemorrhage: An update J Obstet Gynecol.2008;28: 377-81.

12. O’Dwyer V, Hogan JL, Farah NM et al. Maternal mortality and the rising caesarean rate. Int $\mathrm{J}$ Gynecol Obstet. 2012; 116(2):162-164.

13. Makoha FW, Felimban HM, Fathuddin MA et al. Multiple caesarean section morbidity. Int Gynecol Obstet.2004; 87: 227-32.

14. Yang Q, Wen SW, Oppenheimer L, et al. Association of caesarean delivery for first birth with placenta praevia and placental abruption in second pregnancy. BJOG.2007; 114(5):609-13.

15. Crane JMG, Van den Hof MC, Dodds L et al. Maternal complications with placenta previa. Am J perinatology.2000;17(2): 101-105.

16. Olive EC, Roberts CL, Algert CS and Morris JM: Placenta praevia: "Maternal morbidity and place of birth .Australian and New Zealand Journal of Obstetrics and Gynecology.2005; 45(6):499-504.

17. Cook J, Dhanjal M, Jarvis S et al. Multiple repeated caesarean section. UK Obstetrics Surveillance system.2008)

18. Patel MK, Suleiman HA and Choudhary GA. The effects of repeated caesarean sections on maternal and fetal outcomes. Saudi Journal of Medicine and Medical sciences. 2015;3(1): 44-49.

19. Arain FR, Al Bizrah NA, Jawad A, Tarem D. Incidence of placenta previa, Management and maternal outcome in region of Taif.KSA. Journal of Dental and Medical Sciences.2016 ; 15(10): 122-126.

20. Kollmann M, Gaulhofer J, Lang U, et al. Placenta praevia: Incidence, risk factors and outcome. The Journal of Maternal-Fetal and Neonatal Medicine.2016;29(9): 1395-8. 